\title{
Inovação Tecnológica na Agricultura Orgânica: estudo de caso da certificação do processamento pós-colheita
}

\author{
Eduardo Mello Mazzoleni ${ }^{1}$ \\ Luiz Guilherme de Oliveira ${ }^{2}$
}

\begin{abstract}
Resumo: A tecnologia empregada na agricultura orgânica e no processamento pós-colheita vem desenvolvendo um padrão produtivo bastante distinto à agricultura "moderna". O desejo do consumidor de adquirir um alimento que não venha causar risco a sua saúde foi alterando o mercado, e o produto orgânico passa a ser preferido e mais valorizado por um segmento da população. Sem o uso de agroquímicos, a agricultura orgânica recupera conceitos tradicionais e se renova a partir da utilização de inovações tecnológicas intensivas em conhecimento. A proposta deste trabalho é estudar os aspectos da inovação no processamento pós-colheita de uma fazenda de produção orgânica, especificamente na embalagem e no processamento mínimo, impulsionada pela exigência de certificação, em um estudo de caso na região do Centro-Oeste brasileiro. $\mathrm{O}$ artigo aborda as características históricas da inovação na agricultura, as dificuldades de investimento em tecnologias na agricultura orgânica e a questão da certificação. Este estudo de caso foi realizado a partir de uma série de entrevistas. Os resultados fazem perceber que as modificações nas rotinas internas da empresa e a adoção de uma série de normas técnicas viabilizaram o processo de inovação, possibilitando a adequação da fazenda para obter a certificação exigida para atender ao mercado.
\end{abstract}

Palavras-chave: agricultura orgânica, inovação tecnológica, certificação, processamento pós-colheita.

1 Mestre em Agronegócios na Universidade de Brasília (UnB). Doutorando em Administração na UnB. Professor do curso de Administração da Faculdade da Terra de Brasília (FTB) e do curso de Agronomia da União Pioneira de Integração Social da Faculdades Integradas (Upis). Analista de comércio exterior do Ministério da Agricultura, Pecuária e Abastecimento (Mapa). E-mail: eduardo.mazzoleni@agricultura.gov.br, eduardo.mazzoleni@yahoo.com.br.

2 Economista, Doutor em Política Científica e Tecnológica na Universidade Estadual de Campinas (DPCT/Unicamp), Brasil. Professor da Universidade de Brasília FUP/UnB, PPGA/UnB, Pesquisador do Grupo de Estudos do Sistema Agroindustrial (GESA/ UnB/FUP). E-mail: lgoliveira@unb.br 


\begin{abstract}
The technology used in organic farming and post-harvest processing is contributing to the development of production standards that are quite different from those of modern agriculture. The desire of consumers to acquire food that does not endanger their health is changing the market; and organic products are coming to be preferred and valued by a growing segment of the population. In not using chemical products, organic farming returns to and renews traditional farming concepts by means of knowledgeintensive technological innovations. The objective of the case study reported here was to investigate innovations in the post-harvest processing of organic produce on a farm in the Central-Western region of Brazil. The innovation process was driven by certification requirements, specifically those dealing with minimal processing and packaging. The article addresses the historic characteristics of innovation in agriculture, the difficulties of investment in technologies in organic farming and the competitiveness of the present market. The study was conducted through a series of interviews. Results demonstrate that the modifications in internal routines and the adoption of technical standards induced by the certification process were responsible for the innovations, permitting the production of high-standard organic produce for the market.
\end{abstract}

Key-words: organic farming, technological innovation, certification, post-harvest processing.

Classificação JEL: Q01, Q13, Q56.

\title{
1. Introdução
}

Os estudos sobre inovação normalmente abordam a evolução tecnológica dos setores industriais. As pesquisas teóricas e empíricas analisam, quase que exclusivamente, as mudanças que ocorrem nas fronteiras tecnológicas envolvendo os ramos industriais. O presente trabalho estuda os aspectos da inovação no processamento pós-colheita da produção orgânica, especificamente na embalagem e no processamento mínimo. O estudo de caso foi usado para investigar uma fazenda de produtos orgânicos da região Centro-Oeste do Brasil. A fazenda foi impulsionada a inovar pela exigência de certificação de um de seus clientes mais importantes, uma grande rede de supermercados.

A inovação no processamento pós-colheita, estudada nesta pesquisa, está inserida no nicho de mercado específico da agricultura orgânica, fato que levou a uma análise das duas realidades que evoluíram e convivem em paralelo, quais sejam, a agricultura "moderna" e a orgânica. Embora a primeira seja a mais relevante economicamente no Brasil, a agricultura orgânica vem crescendo muito nos últimos anos e representa uma alternativa concreta de desenvolvimento sustentável. Segundo Willer, Sorensen e Yussefi-Menzler (2008), a agricultura orgânica apresenta dados estatísticos em 132 países, perfazendo, no final de 
2006, um total mundial de 30,4 milhões de hectares com manejo orgânico, em mais de 700.000 fazendas. O Brasil, no mesmo levantamento, utiliza uma área de 800.000 hectares para a produção orgânica.

Ao se observar a produção agrícola, pode-se perceber que a agricultura "moderna" permite o uso dos solos de forma intensiva, baseada em pacotes tecnológicos de elevada produtividade. A eficiência desse sistema produtivo é alcançada pelo uso de plantas selecionadas e padronizadas para altos desempenhos, embora necessitem de elevadas doses de insumos químicos e mecanização para produzirem. Entretanto, esse padrão de produção não se ajustou à agricultura de forma generalizada, aumentando a diferença entre agricultores fortes e aqueles que não conseguiram elevar suas receitas ou produtividades (MAZOYER e ROUDART, 2007).

Por outro lado, a agricultura orgânica vem desenvolvendo um padrão produtivo bastante distinto à agricultura "moderna". Sem o uso de insumos químicos, a alternativa orgânica busca recuperar conceitos tradicionais e inova na utilização de tecnologias agroecológicas. Assim, a agricultura orgânica consegue aprofundar o conhecimento científico e tecnológico para tratar a propriedade rural, principalmente a familiar, como um organismo particular, dinâmico e eficiente (ASSIS e ROMEIRO, 2005).

Inicialmente, o artigo aborda a fundamentação teórica das características da inovação na agricultura e da exigência de certificação dos mercados orgânicos. Em seguida, é apresentado um estudo de caso de uma fazenda orgânica que necessitou inovar sua agroindústria de processamento de hortaliças, mostrando os materiais e métodos utilizados, assim como os resultados e a discussão dos principais aspectos encontrados. Por fim, são apresentadas as conclusões relevantes e as sugestões para pesquisas futuras.

\section{Fundamentação teórica}

O referencial teórico, inicialmente, abordará a evolução da inovação tecnológica na agricultura, fazendo um relato das revoluções agrícolas. Posteriormente, será exposta a questão do processo de inovação e dos obstáculos para os investimentos em pesquisa na agricultura orgânica. Concluindo a fundamentação teórica, serão desenvolvidas as exigências do mercado para produtos orgânicos, destacando a necessidade de certificações.

\subsection{Inovações tecnológicas na agricultura}

A Primeira Revolução Agrícola foi caracterizada por uma profunda mudança tecnológica, baseada na utilização da tração animal e, principalmente, na substituição do pousio pela integração da agricultura/pecuária, com o emprego do fertilizante animal. O pousio é a interrupção de um ou mais anos sem plantar 
uma mesma área, para a recomposição da fertilidade, exigindo sempre novas áreas para cultivo. A tração animal permitiu a passagem do pousio ao cultivo anual, graças ao plantio de forragens e rotação com leguminosas, aproximando a agricultura da pecuária. "O cultivo e a criação de animais formaram progressivamente os alicerces das sociedades europeias. E esse longo acúmulo acabou por provocar um dos mais importantes saltos de qualidade da civilização humana: o fim da escassez crônica de alimentos." (VEIGA, 1991, p. 21).

A integração agricultura e pecuária tornava o novo sistema produtivo dependente de matéria orgânica para fertilização constante da terra. $\mathrm{O}$ incremento da diversidade de plantas e adoção de vários métodos de cultivo permitiu "aumentar a lotação de cabeças de gado nas propriedades, beneficiando a fertilidade dos solos, principalmente os solos fracos" (EHLERS, 1994, p. 11).

O uso de fertilizante orgânico, do plantio de forrageiras e a rotação com leguminosas não era uma novidade; já era usado nos jardins e pomares (VEIGA, 1991). Dessa forma, conclui-se que a Primeira Revolução Agrícola não era uma descoberta, mas, literalmente uma inovação, isto é, a utilização prática do conhecimento, resultando em ganho econômico.

A Segunda Revolução Agrícola foi marcada pela inovação dos fertilizantes químicos. Em 1840, o químico alemão Justus von Liebig publica a teoria da nutrição mineral das plantas. Segundo Acot, citado por Ehlers (1994), Liebig é considerado o maior precursor da agricultura moderna. Sua abordagem parte do conceito da utilização exclusiva de substâncias químicas no tratamento do solo, atingindo a estrutura produtiva da Primeira Revolução Agrícola.

Antecedendo a Revolução Verde, as descobertas das utilizações da química na agricultura foram o pilar que faltava na tentativa de domínio da natureza. Todas as inovações tecnológicas verticais (setor agrícola) e transversais (setores da química, genética, mecânica) são reunidas por volta de 1960 a 1970 e direcionadas à agricultura (EHLERS, 1994). Tal concepção era a esperança ilimitada de combate à miséria no mundo. Instituições internacionais e governos dos países subdesenvolvidos se lançaram de corpo e alma nessa empreitada. Segundo Navarro (2001, p. 83-84), "após lenta acumulação de inovações anteriores, constituiu-se uma nova e acabada 'compreensão de agricultura' [...] Alicerçada no que foi genericamente intitulado de 'revolução verde', materializou-se de fato sob um padrão tecnológico".

A Revolução Verde se predispôs a dominar a natureza, baseada na indústria química de adubos sintéticos e de agroquímicos, bem como no uso intensivo de energia, pesquisa genética, máquinas e equipamentos (BEZERRA e VIEGA, 2000). Essa modalidade de agricultura é simplificada a ponto de adequar qualquer meio ambiente para o gerenciamento padronizado por pacotes tecnológicos. Para Valdinoci (1979), a Revolução Verde não se contentava apenas em abrir espaços, era preciso desestimular a agricultura 'tradicional', proclamada como antiquada e irreversivelmente ultrapassada. 
Nesse contexto, nenhuma pesquisa poderia ser feita fora da modernidade química, nenhum financiamento poderia contemplar sistemas agrícolas rudimentares, nenhum consumidor mereceria um produto que não fosse seguro e moderno. Seguro na visão de que o alimento produzido artesanalmente era menos nutritivo e corria-se o risco de contaminações biológicas por falta de higiene e padronização do sistema produtivo. Entretanto, as consequências surgiram e mostraram que o uso da natureza é limitado e que a recuperação do meio ambiente degradado é difícil, principalmente por substâncias químicas e por práticas agrícolas vinculadas à monocultura.

Porém, a euforia do caminho seguro logo mostrou seus equívocos: "a erosão e a perda da fertilidade dos solos; destruição florestal; a dilapidação do patrimônio genético e da biodiversidade; a contaminação dos solos, da água, dos animais silvestres, do homem, do campo e dos alimentos" (EHLERS, 1994, p. 24).

Os riscos e os acidentes do modelo de agricultura dependente de agroquímicos provocaram uma reação crítica da sociedade. O consumidor iniciou um questionamento das consequências do uso de agroquímicos, mesmo que de forma regulamentada. Entra em cena um novo conceito, a segurança do alimento, que representa a certeza do consumidor em adquirir um alimento que não venha causar risco a sua saúde (SPERS, 2000).

Essa nova realidade foi alterando o mercado consumidor e, pouco a pouco, as exigências foram se modificando. O produto, que era desvalorizado por não ter a procedência na moderna agricultura química padronizada, passa a ser preferido e mais valorizado, com um prêmio no preço por ser orgânico (DAROLT, 2002; ORMOND, 2002; SAHOTA, 2004; VOSSENAAR et al., 2004).

\subsection{Obstáculo para o investimento em inovação na agricultura orgânica}

Os fatores econômicos, institucionais e sociais são decisivos na seleção das inovações em todos os níveis, desde a pesquisa até a produção. A seleção ocorre entre as possíveis 'trajetórias', estando baseada em critérios evidentes e amplos, como exequibilidade, negociabilidade e rentabilidade. Um poderoso critério de seleção reside na capacidade da nova tecnologia reduzir custos, em particular, economizar mão de obra. A colocação de máquinas no lugar de mão de obra muitas vezes é o processo predominante na busca de novas tecnologias (DOSI, 2006).

Quanto ao processo de inovação, deve-se ter em mente que ele se materializa através do mercado. As organizações precisam determinar se o custo total por unidade produzida com a inovação será inferior ao sistema até então praticado. A administração privada adotará o "novo método de produção que considere capaz de produzir um número de renda futura por unidade do valor correspondente dos investimentos futuros, ambos descontados do presente, do que o método atualmente em uso" (SCHUMPETER, 1984, p. 123). 
Hall (2007), analisando vários estudos, constata que existe uma ideia consistente sobre os fatores necessários para ocorrer a inovação na agricultura. $\mathrm{O}$ ambiente para proporcionar mudanças tecnológicas inclui: os conhecimentos provenientes de múltiplas origens, englobando os saberes utilizados pelos próprios agricultores; as interações dessas diferentes fontes de conhecimento; a adaptação dessas interações e dos processos resultantes para cada contexto particular; bem como a repercussão dessas adaptações particulares nas rotinas e tradições históricas de cada realidade cultural e política.

A difusão tecnológica ocorre por dois mecanismos. Um deles é a utilização da inovação pela firma que a introduz pioneiramente. O segundo mecanismo é a imitação, cuja difusão da inovação é realizada por outras organizações. Certas inovações são intensificadas deliberadamente pelo mecanismo institucional, como a divulgação de novas variedades de sementes. Outras inovações são estimuladas pelos agentes de venda da firma inovadora. Em situação oposta, "o mecanismo institucional pode deter ou bloquear a imitação, tal como o sistema de patentes, que bloqueia a adoção, por uma firma, das inovações patenteadas criadas por um concorrente" (NELSON e WINTER, 2005, p. 385).

A concorrência de mercado constitui uma espécie particular de ambiente de seleção. "Em um sistema evolucionário schumpeteriano estilizado, existe a cenoura e o chicote para motivar as firmas a introduzirem melhores métodos de produção ou produtos." (NELSON e WINTER, 2005, p. 386). O termo 'melhores' corresponde a menores custos de produção ou à determinação do consumidor de comprar a um preço acima do custo, isto é, a apropriabilidade privada dos efeitos da mudança técnica.

A produção orgânica é uma oportunidade tecnológica de desenvolvimento de inovações, porém, necessita da apropriabilidade privada. A apropriabilidade está relacionada com a cumulatividade no âmbito da empresa, resultando em vantagens econômicas específicas para a firma e, assim, permitindo maior competitividade no mercado. A apropriabilidade privada define o grau de compromisso das empresas em relação às atividades de inovação. Essas duas características - oportunidades tecnológicas e apropriabilidade privada - representam condições interligadas para a atividade de inovação nas economias de mercado (DOSI, 2006).

Ao abordar a dinâmica das inovações no agronegócio, Machado (1998) traz o conceito de apropriabilidade das inovações. O autor demonstra que só haverá investimento dos agentes privados se eles conseguirem lucros gerados pelas inovações, apontando que as condições de apropriabilidade diferem entre indústrias e entre tecnologias. Infere-se, dessa forma, que as inovações na agricultura orgânica geralmente não produzem 'vantagens de apropriabilidade' em larga escala para quem desenvolveu essas técnicas. Tal constatação é o grande motivo para que as grandes empresas não sejam estimuladas a desenvolver pesquisa nesse sistema produtivo. $\mathrm{O}$ investimento em pesquisa e desenvolvimento pode ser realizado pelos órgãos oficiais ou pela própria 
iniciativa privada para seu uso direto. Nesta última situação, os agricultores necessitam organizar de forma coletiva seus esforços para dedicarem recursos e conseguirem empreender inovações em suas atividades. A aglutinação de empenhos de forma cooperada é o desafio para viabilidade presente e futura da agricultura orgânica.

Dosi (2006) conclui que o progresso técnico é cumulativo, a vantagem relativa não provém de qualquer 'dotação natural', mas de conhecimentos tecnológicos diferenciais, de experiências que se reproduzem através do tempo. As vantagens comparativas se fortalecem com a própria produção. Isso explica os círculos virtuosos nos países inovadores e os círculos viciosos nos retardatários, definindo os padrões de especialização internacionais e a estabilidade de longo prazo dessas vantagens comparativas nacionais, em termos tecnológicos e comerciais.

A competição e a prosperidade no mercado atual exigirão a organização harmoniosa de todos os atores (empresários, pesquisadores, políticos e consumidores), com o objetivo de mobilizar conhecimentos e continuar inovando, para enfrentar as mudanças constantes do ambiente econômico (HALL, 2007). Nesse sentido, os elos das cadeias produtivas de orgânicos devem interagir para inovar suas rotinas de forma eficiente. A presente pesquisa é uma constatação empírica dessas ideias, cuja unidade de produção agropecuária orgânica estudada precisou alterar sua estrutura física e seus processos cotidianos, na etapa de processamento pós-colheita, para atender às exigências mercadológicas.

Bell (2006) avalia que é muito importante a presença de pesquisadores, empresários, administradores (incluindo os agricultores, que podem fazer todas essas funções) na criação de tecnologias contrárias ao fluxo normal das inovações. O pluralismo do desenvolvimento tecnológico institui um vasto campo de opções para novas formas de organizações direcionadas à agricultura familiar. Esforços devem ser feitos para capturar, avaliar e aprender com essas experiências, permitindo o estabelecimento de projetos que desenvolvam a competitividade das cadeias produtivas e o acesso ao mercado.

\subsection{Mercado de produtos orgânicos e a exigência de certificações}

O termo competitividade deve ser entendido como uma referência entre a empresa e o setor em que ela atua. Dessa forma, uma empresa será competitiva se possuir uma lucratividade superior à média do setor no qual está inserida (MELLO, 2004). Assim, a agricultura orgânica precisa disputar o mercado real, sem ficar apenas na expectativa de que basta produzir bens sem resíduos químicos e de melhor qualidade, utilizando sistemas e processos que respeitam ao meio ambiente. A produção orgânica necessita atingir lucratividade para ser competitiva e sobreviver no atual mercado. 
574 - Inovação Tecnológica na Agricultura Orgânica:

estudo de caso da certificação do processamento pós-colheita

O mercado imprime elevada competitividade aos setores produtivos. Essa crescente competitividade exige um esforço de eficiência não apenas internamente nas unidades produtivas. As relações interorganizacionais não devem mais ser estabelecidas somente pelo intercâmbio fornecedor-cliente. O ambiente local (município ou região) precisa desenvolver um relacionamento de cooperação e de confiabilidade jurídica entre os atores, para viabilizar uma situação de estímulo ao investimento visando às necessidades do mercado.

Ormond (2002), abordando de forma sistêmica a agricultura orgânica, identificou as principais funções que compõem a cadeia produtiva de orgânicos, como pode ser observado na Figura 1.

Figura 1. Esquema da cadeia produtiva de orgânicos.

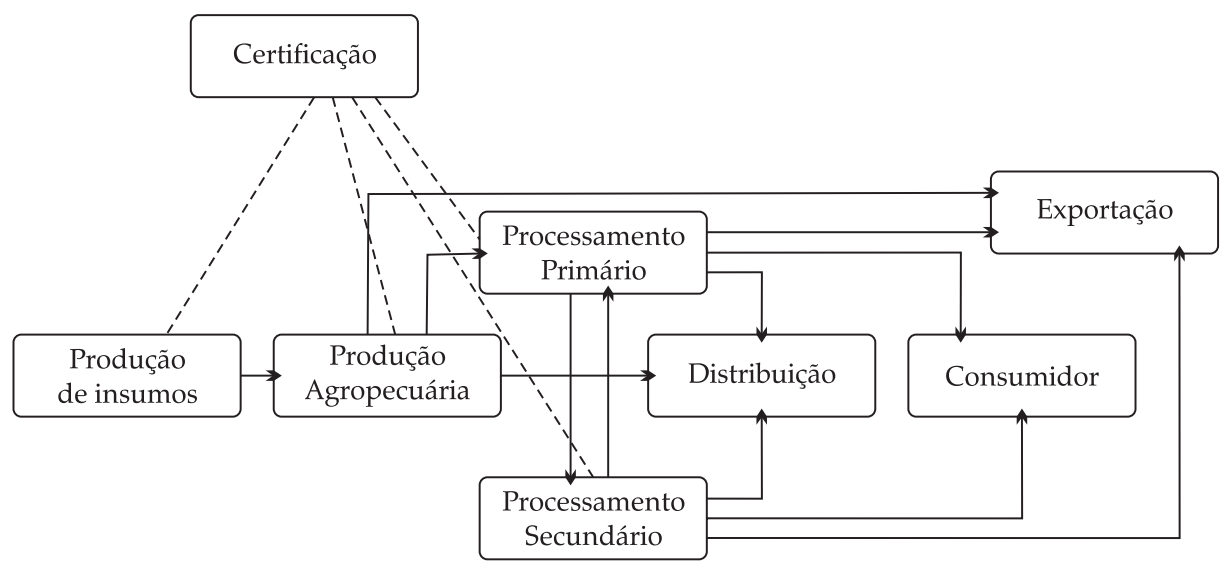

Fonte: Ormond, 2002.

A Figura 1 destaca uma exigência inerente à produção orgânica, que é a certificação. Para entender a necessidade de certificação de orgânicos, é importante distinguir três tipos de produtos: i) bens de procura, ii) bens de experiência e iii) bens de crença. Para fins analíticos, o primeiro grupo (bens de procura) oferece todas as informações relevantes para a transação antes da troca. Para os bens de experiência, alguns dados - como critérios de textura, sabor e saúde - só podem ser obtidos após a troca ou após o consumo. No terceiro grupo (bens de crença), algumas informações relevantes não são obtidas nem após o consumo (BATALHA e SILVA, 2001). Nesse último grupo estão inseridos os orgânicos, visto que um consumidor de uma grande cidade, por exemplo, observando apenas o produto, não poderá identificar se o alimento que vai comprar, comprou ou mesmo já consumiu, foi produzido em um sistema orgânico que respeita o meio ambiente. Esse tipo de produto necessita de certificação. 
Segundo a International Organization for Standardization - ISO (2005), certificação significa a emissão escrita da garantia - o certificado - por uma empresa externa e independente: a certificadora. Essa empresa realiza a auditoria no sistema de administração e verificação da empresa que deseja o certificado. A fazenda orgânica, no caso deste artigo,éa empresa que estábuscando o certificado, que será emitido se seus procedimentos estiverem conforme os requerimentos especificados no padrão pré-definido da certificadora. A certificação tem dois objetivos. Do lado da oferta, o intuito é oferecer procedimentos e padrões básicos, criando instrumento de exclusão e seleção de firmas e produtos. Do lado da demanda, visa-se fornecer uma informação ao consumidor que signifique um mecanismo de redução de assimetrias informacionais, tornando o mercado mais eficiente. Além de beneficiar os consumidores, por deixá-los mais seguros, a certificação cria incentivos à cooperação horizontal e vertical entre as empresas.

A certificação tem várias similaridades e pontos comuns com o conceito de padronização. Tal processo é um passo à frente da padronização do ponto de vista de coordenação de sistemas agroindustriais. A certificação é mais detalhada, com instrumentos de exclusão aos que não seguirem as regras (NASSAR, 2003).

A comercialização e as exigências do mercado são, normalmente, as maiores dificuldades individuais para o ingresso na produção orgânica. $O$ presente trabalho se dedicará a analisar um estudo de caso que produz com preservação ambiental - pela utilização da agricultura orgânica -, mas que precisa respeitar as cobranças de seus compradores. A fazenda orgânica estudada precisou inovar para obter a certificação de marca própria dos seus clientes, as grandes redes de supermercados.

\section{Metodologia}

Este trabalho foi feito a partir de um estudo de caso, analisando uma única empresa. Foram levantadas as capacidades tecnológicas da agroindústria de processamento de hortaliças de um empreendimento de produção orgânica do Centro-Oeste brasileiro. O método de estudo de caso é uma estratégia que objetiva o entendimento da dinâmica presente em determinados grupos, cuja finalidade é fazer a descrição de um fenômeno.

$\mathrm{O}$ estudo de caso permite aprofundar e tratar uma multiplicidade de dimensões (MARTINS, 2006). O método é empregado quando o pesquisador tem pouco controle sobre os eventos inseridos no contexto da vida real. Esse tipo de estudo é considerado apropriado para, além de descrever fenômenos, explorar a situação problema, quando seus resultados são utilizados como pontos de partida para uma pesquisa adicional (YIN, 2001).

A pesquisa empregou como origem de dados os documentos e registros em arquivos disponibilizados na própria fazenda. Adicionalmente, foram feitas entrevistas com gerentes e proprietário do empreendimento. De forma 
complementar, houve observações diretas na produção agropecuária e na agroindústria estudada. A coleta das informações se deu em dezembro de 2007. O objetivo de reunir várias fontes de dados é realizar o processo denominado de triangulação, para desenvolver linhas convergentes de investigação e alcançar uma maior confiabilidade do estudo de caso.

A "fazenda orgânica estudada" (FOE) é um empreendimento agropecuário que emprega mais de 140 trabalhadores, produzindo apenas pelo conceito de agricultura orgânica. Possui uma área de 129 hectares, sendo 32 hectares de horta, 45 hectares de pastagem e o restante voltado a reservas ambientais.

A FOE apresenta um organograma estabelecido da seguinte forma: a Diretoria é o nível deliberativo superior, composta dos proprietários (um engenheiro florestal e uma engenheira agrônoma); o Conselho Técnico é o fórum deliberativo, formado pelos proprietários, dois engenheiros agrônomos internos, um engenheiro de alimentos, três técnicos agropecuários, um encarregado da agroindústria, um trabalhador da produção e um engenheiro agrônomo consultor externo; a Equipe Técnica é o conjunto dos gerentes responsáveis pela execução das atividades; os Encarregados de Grupos; os Líderes de Grupos; e os trabalhadores da fazenda e da agroindústria.

\section{Resultados e discussão}

A FOE é uma empresa composta de quatro áreas operacionais distintas e complementares: a) a produção orgânica, que reúne a produção vegetal de hortaliças e a pecuária de leite; b) a agroindústria de processamento de hortaliças, que embala produtos in natura e alguns minimamente processados (objeto deste estudo); c) a agroindústria de processamento do leite, com fabricação de produtos industrializados; e d) a área de comercialização.

A área da agropecuária orgânica, trabalhada há mais de 22 anos, já desenvolve mudanças contínuas em seus produtos e processos. A produção de hortaliças está consolidada e apresenta um processo tecnológico muito desenvolvido, com programação de plantio até a safra de 2010. A estrutura administrativa e o quadro de funcionários realizam sempre melhorias incrementais em sua produção agropecuária orgânica, em um nível de ajuste fino de verificação e reavaliação constante de seus procedimentos. Por questão de direcionamento desta pesquisa, a área de produção agropecuária orgânica, bem como a agroindústria de processamento de leite e a comercialização não são detalhadas neste trabalho.

O foco se direciona especificamente à agroindústria de processamento de hortaliças da FOE, nas etapas de embalar produtos in natura e de algumas linhas de elaboração de produtos minimamente processados.

A FOE foi induzida a inovar na infraestrutura e no controle da sua agroindústria de processamento de hortaliças, devido às cobranças do mercado, 
que se materializaram nas exigências das certificadoras de marca própria do setor de distribuição. Para continuar comercializando com um de seus clientes mais importantes, uma grande rede varejista brasileira de abrangência nacional, a FOE sentiu-se impelida a realizar mudanças.

\subsection{Implantação do manual dos procedimentos operacionais padronizados (POP)}

As principais alterações introduzidas na FOE foram as exigências da descrição de rotinas, da existência de controles escritos e da melhoria nos fluxos de produção. Essa situação desafiou a direção e a equipe de técnicos da fazenda, que resolveram implantar um manual de suas rotinas. O esforço conjunto resultou na elaboração do manual dos "Procedimentos Operacionais Padronizados" (POP). A seguir, são enumeradas as unidades do manual POP.

Unidades do manual de Procedimentos Operacionais Padronizados (POP):

- POP 1 - Programa de higienização de instalações, equipamentos e utensílios;

- POP 2 - Controle da potabilidade da água;

- POP 3 - Saúde, higiene e treinamento de manipuladores;

- POP 4 - Manejo de resíduos;

- POP 5 - Manutenção preventiva e calibração de equipamentos;

- POP 6 - Controle integrado de pragas (domésticas);

- POP 7 - Seleção de matérias-primas e ingredientes;

- POP 8 - Recolhimento de produtos (reclamações);

- POP 9 - Recepção de produtos;

- POP 10 - Procedimentos para preparo de produtos in natura;

- POP 11 - Embalagem e acondicionamento de produtos in natura; e

- POP 12 - Expedição de produtos.

Cada unidade do manual POP reúne três cadernos com as seguintes informações: a descrição do procedimento operacional padronizado; o conjunto dos registros de qualidade; e o detalhamento das instruções de trabalho de cada atividade a ser desenvolvida.

A primeira vistoria que a FOE recebeu de auditoria da certificadora de marca própria da rede de varejo foi no dia 10 de janeiro de 2007. O certificado só é concedido se a conformidade for superior a 69\% das normas da certificadora. Nessa primeira verificação, a FOE obteve uma conformidade de aproximadamente $35 \%$ das exigências da certificadora em relação ao processo da agroindústria. Por não atingir o padrão mínimo, a FOE não chegou a receber a vistoria na parte da produção agropecuária orgânica.

Dois meses depois, na segunda inspeção, a agroindústria da FOE já obteve uma conformidade de mais de $85 \%$ do exigido pela mesma certificadora. Como consequência, foi também realizada a vistoria no campo, na qual a produção 
agropecuária orgânica recebeu uma conformidade em torno de $80 \%$ das regras previstas pela certificadora da grande rede de varejo.

A capacidade de inovar, motivada por uma exigência externa do mercado, foi muito rápida para a FOE. Esse dinamismo é consequência da própria história e da estrutura da unidade empresarial de produção agrícola orgânica.

A FOE exercita plenamente a sua determinação de agir com uma estrutura empresarial. Prova disso são as consultorias em diversas áreas: na produção agrícola, em administração, no segmento da agroindústria e também no campo financeiro. A empresa tem um plano estratégico, que inclui: a visão, a missão e os valores do negócio; diagnósticos do ambiente externo - com as oportunidades e ameaças - e do interno, com os pontos fortes e fracos; objetivos estratégicos, desdobrados em metas organizacionais e detalhando até o plano de ação semanal, decidido nas atas do Conselho Técnico.

As inovações na infraestrutura foram indispensáveis, principalmente, para dar suporte às mudanças marcantes dos processos na agroindústria. Essas inovações foram basicamente de gestão e informação. Todas as pessoas que trabalham foram motivadas a desenvolver melhorias contínuas, reforçando para cada funcionário a necessidade de avanços constantes. A seguir, serão relatadas algumas das inovações mais significativas encontradas na FOE.

\subsection{Principais inovações desenvolvidas}

As mudanças mais importantes na FOE foram de origem operacional, isto é, alterações nos processos de beneficiamento básico da agroindústria. Entretanto, inicia-se a descrição das inovações pelas mudanças que ocorreram na infraestrutura da unidade de embalar produtos in natura e minimamente processados. Pelas observações realizadas, infere-se que a infraestrutura é, muitas vezes, condição indispensável para inovar. Tal condição, porém, comumente não é suficiente; a melhoria precisa da adequação do processo pelo estabelecimento de novas rotinas operacionais.

A infraestrutura da agroindústria foi reforçada nas instalações: o piso comum recebeu revestimento cerâmico; foi colocado um forro de material plástico adequado para isolamento e de fácil limpeza; foi instalada uma iluminação calculada pelos coeficientes técnicos recomendados; decidiu-se pela utilização de vidros e telas para isolar o prédio do ambiente externo; foram adquiridos paletes para suspender as caixas de produtos durante o manuseio; foram afixadas placas para identificar cada espaço com a sua função dentro do fluxo de atividades; além da construção de telhados para o recebimento e a expedição de mercadorias.

As instalações receberam ar condicionado para evitar os excessos de temperatura ambiente, melhorand o o desempenho dos funcionários e o controle sanitário, impedindo possíveis contaminações. Outra alteração foi a montagem de uma câmara refrigerada para acomodar os produtos embalados antes de 
serem transportados. Essa mudança foi tão importante que já foi demandada a instalação da segunda câmara.

Outros importantes investimentos estiveram relacionados a equipamentos para atender a requisitos de higiene, de funcionalidade e de controle, entre eles: dosador para tratamento da água, máquina para lavar tubérculos, mesas de inox, mais caixas de manuseio de produtos, novas etiquetadoras, cortinas transparentes para as portas, carrinho para transportar caixas e carreta para receber e transportar resíduos.

Do ponto de vista do gerenciamento dos processos, as significativas inovações aconteceram em várias atividades relacionadas aos POPs. Uma das mudanças que mais se destacam é vinculada ao POP 9, sobre a recepção dos produtos que vêm da área de produção agrícola orgânica. Antes da certificação, os produtos eram recebidos e somente as pessoas que estavam operando sabiam de sua procedência e etapas pelas quais já tinham passado. Essas informações não permitiam o perfeito fluxo do processamento. Com a definição e implantação dos procedimentos operacionais padronizados, todas as caixas de qualquer produto têm uma etiqueta identificando seu histórico, permitindo os registros apropriados e a fluidez para prosseguir no processo pré-definido. Essa mudança permitiu economia de tempo, evitou desperdícios, facilitou os controles de custos e viabilizou o controle da rastreabilidade dos produtos, desde a colheita até a colocação do código de barra.

Na sequência dessa melhoria, as alterações introduzidas no POP 10, sobre os procedimentos para preparo de produtos in natura, são fundamentais dentro do conjunto de inovações da FOE. Os processos experimentaram drásticas mudanças em seus fluxos durante a etapa de descrição dos procedimentos operacionais que seriam padronizados. Essa fase colaborou para a descoberta de novas rotinas e quebra de barreiras operacionais que não faziam sentido algum, como mesas encostadas na parede para empilhar produtos já embalados. Tal prática negativa produzia diminuição do fluxo da produção, gasto de tempo dobrado para tirar da mesa e colocar os produtos nas caixas para transporte, além de danificar as embalagens que ficavam inapropriadamente acomodadas. Consequentemente, a descrição do POP 10 reduziu o fluxo cruzado da produção, aumentou a produtividade e garantiu uma qualidade mais elevada e padronizada.

As alterações feitas no POP 3, que se referem à saúde, higiene e treinamento dos manipuladores, foram importantes para consolidar as demais inovações. $\mathrm{O}$ plano de treinamento dos manipuladores foi um forte auxílio para capacitar as pessoas no início da execução do POP. Os cursos ajudavam os funcionários a entender e a se interessar pelas instruções expressas que cada atividade passava a ter, treinando para a nova realidade de funcionamento da agroindústria. O POP 3 também introduziu um cronograma dos exames de saúde de cada trabalhador e a fixação de placas com as instruções para orientar a higiene pessoal.

Outras mudanças nos processos também trouxeram benefícios para o funcionamento da agroindústria e boa pontuação na lista de verificação de 
conformidade da certificadora. Aatividade demanejodos resíduos foi padronizada, pelo POP 4, com o simples investimento da carreta para reunir e transportar os resíduos. Essa prática evita o acúmulo de resíduos, próximo da parede do prédio de processamento, eliminando a possibilidade de contaminação. Além disso, por se tratar de resíduos de parte das hortaliças colhidas no mesmo dia, esse manejo permite o aproveitamento integral deste material para a alimentação animal.

Finalizando as principais inovações pesquisadas, mesmo sem descrever todas, exemplifica-se, ainda, a importância que as mudanças proporcionaram para a melhoria da FOE. Devido à necessidade de determinar os procedimentos do controle integrado de pragas domésticas dentro da agroindústria de hortaliças (POP 6), detectou-se que era mais econômico e seguro contratar uma empresa terceirizada. Esse procedimento estabeleceu os locais para controle e definiu pela contratação de empresa qualificada especificamente no assunto para realizar esta tarefa, respeitando as limitações que a produção orgânica estabelece para o controle.

As descrições de todas as inovações, de forma abrangente, podem ser observadas no Quadro 1. As informações estão dispostas com base nas unidades do manual POP e divididas, cronologicamente, pelas situações encontradas antes da obtenção da certificação, a atual realidade encontrada e as expectativas de mudanças para o futuro. As observações estão divididas em relação a dois aspectos básicos em inovação: a infraestrutura, que representa a forma que o capital está imobilizado para dar suporte às mudanças, e os processos, que são efetivamente a utilização da infraestrutura, da tecnologia e do conhecimento para implantar as inovações.

Quadro 1. Inovações relacionadas aos Procedimentos Operacionais Padronizados (POP).

\begin{tabular}{|c|c|c|}
\hline $\begin{array}{l}\text { Anterior } \\
\text { Infraestrutura: } \\
\text { - Piso de cimento bruto. } \\
\text { - Ausência de forro. } \\
\text { - Iluminação não equilibrada. } \\
\text { - Aberturas superiores que permi- } \\
\text { tiam entrada de pássaros. } \\
\text { - Ambiente de trabalho com exces- } \\
\text { sos de temperatura. } \\
\text { - Caixas com produtos colocadas } \\
\text { no chão. } \\
\text { - Inexistência de placas identifica- } \\
\text { doras. } \\
\text { - Recebimento e expedição sem co- } \\
\text { bertura para o sol e chuva. } \\
\text { Processo: } \\
\text { - Ausência de procedimento escri- } \\
\text { to; as atividades eram definidas } \\
\text { verbalmente. }\end{array}$ & $\begin{array}{l}\text { Atual } \\
\text { - Infraestrutura: } \\
\text { - Revestimento cerâmico do piso. } \\
\text { - Instalação de forro plástico. } \\
\text { - Iluminação dentro das recomen- } \\
\text { dações técnicas de luminosidade. } \\
\text { - Colocação de vidros ou telas em } \\
\text { todo o prédio. } \\
\text { - Colocação de ar condicionado. } \\
\text { - Palete para afastar as caixas do } \\
\text { chão. } \\
\text { - Placas identificando os locais. } \\
\text { - Telhado na parte externa do rece- } \\
\text { bimento e expedição. } \\
\text { Processo: } \\
\text { - Utilização das descrições dos pro- } \\
\text { cedimentos definidos no manual. }\end{array}$ & $\begin{array}{l}\quad \text { Futuro } \\
\text { Processo: } \\
\text { - Verificação e reavaliação constante } \\
\text { dos procedimentos. }\end{array}$ \\
\hline
\end{tabular}




\begin{tabular}{|c|c|c|}
\hline $\begin{array}{l}\text { Anterior } \\
\text { Infraestrutura } \\
\text { - Poço artesiano. } \\
\text { - Filtro. } \\
\text { - Uso de pastilhas de cloro. } \\
\text { Processo } \\
\text { - Teste da qualidade da água. }\end{array}$ & \begin{tabular}{l}
\multicolumn{1}{c}{ Atual } \\
Infraestrutura: \\
- Dosador para aplicar o cloro. \\
Processo: \\
- Registro da qualidade da água.
\end{tabular} & $\begin{array}{l}\quad \text { Futuro } \\
\text { Processo: } \\
\text { - Verificação e reavaliação constan- } \\
\text { te dos procedimentos. }\end{array}$ \\
\hline \multicolumn{3}{|c|}{ POP 3 - Saúde, higiene e treinamento dos manipuladores } \\
\hline $\begin{array}{l}\text { Anterior } \\
\text { Processo: } \\
\text { - Falta de registro de quando os } \\
\text { trabalhadores faziam os exames } \\
\text { de saúde. } \\
\text { - Inexistência de um plano de trei- } \\
\text { namentos. } \\
\text { - Orientação apenas verbal do tra- } \\
\text { balho. } \\
\text { - Ausência de placas para orientar } \\
\text { a higiene. } \\
\text { - Inexistência de procedimentos para } \\
\text { receber visitantes. }\end{array}$ & $\begin{array}{l}\text { Atual } \\
\text { Processo: } \\
\text { - Registro dos exames de saúde dos } \\
\text { trabalhadores. } \\
\text { - Controle dos treinamentos. } \\
\text { - Instrução expressa dos trabalhos. } \\
\text { - Placas para orientar a higiene e as } \\
\text { atividades. } \\
\text { - Regras para receber visitantes. }\end{array}$ & $\begin{array}{l}\quad \text { Futuro } \\
\text { Processo: } \\
\text { • Verificação e reavaliação constante } \\
\text { dos procedimentos. }\end{array}$ \\
\hline \multicolumn{3}{|l|}{ POP 4 - Manejo de resíduos } \\
\hline $\begin{array}{l}\text { Anterior } \\
\text { Infraestrutura: } \\
\text { - Lixo depositado no lado externo } \\
\text { do prédio e encostado na parede. } \\
\text { Processo: } \\
\text { - Acumulação de lixo até a remoção. } \\
\text { - Aproveitamento parcial para ali- } \\
\text { mentação dos animais da fazenda. }\end{array}$ & $\begin{array}{l}\text { Atual } \\
\text { Infraestrutura: } \\
\text { - Carreta para reunir e transportar } \\
\text { os resíduos, proporcionando eco- } \\
\text { nomia de manuseio. } \\
\text { Processo: } \\
\text { - Lixo afastado do prédio. } \\
\text { - Remoção diária do resíduo, evi- } \\
\text { tando contaminações e melhoran- } \\
\text { do o aproveitamento para alimen- } \\
\text { tar os animais. }\end{array}$ & $\begin{array}{l}\quad \text { Futuro } \\
\text { Processo: } \\
\text { - Verificação e reavaliação constan- } \\
\text { te dos procedimentos. }\end{array}$ \\
\hline \multicolumn{3}{|c|}{ POP 5 - Manutenção preventiva e calibração de equipamentos } \\
\hline $\begin{array}{l}\text { Anterior } \\
\text { Processo: } \\
\text { - Manutenção irregular, dependen- } \\
\text { do do funcionário que realizasse. }\end{array}$ & \begin{tabular}{|l|}
\multicolumn{1}{|c|}{ Atual } \\
Processo: \\
• Utilização dos registros de padro- \\
nização dos procedimentos.
\end{tabular} & $\begin{array}{l}\text { Futuro } \\
\text { Processo: } \\
\text { • Verificação e reavaliação constan- } \\
\text { te dos procedimentos. } \\
\end{array}$ \\
\hline \multicolumn{3}{|c|}{ POP 6 - Controle integrado de pragas (domésticas - dentro da agroindústria) } \\
\hline $\begin{array}{l}\text { Anterior } \\
\text { Infraestrutura: } \\
\text { - Dificuldade de controle de pra- } \\
\text { gas, pois as caixas com os produ- } \\
\text { tos ficavam encostadas no chão. } \\
\text { Processo: } \\
\text { - Controle em locais aleatórios. } \\
\text { - Operação feita por pessoa não trei- } \\
\text { nada especificamente para contro- } \\
\text { le de pragas. }\end{array}$ & \begin{tabular}{l}
\multicolumn{1}{c}{ Atual } \\
Infraestrutura: \\
- Palete para afastar caixas do chão. \\
Processo: \\
- Descrição dos locais de controle. \\
- Contratação de empresa externa, es- \\
pecializada em controle de pragas.
\end{tabular} & $\begin{array}{l}\quad \text { Futuro } \\
\text { Processo: } \\
\text { - Verificação e reavaliação constan- } \\
\text { te dos procedimentos. }\end{array}$ \\
\hline
\end{tabular}


Inovação Tecnológica na Agricultura Orgânica: estudo de caso da certificação do processamento pós-colheita

\begin{tabular}{|c|c|c|}
\hline \multicolumn{3}{|c|}{ POP 7 - Seleção de matérias-primas e ingredientes } \\
\hline $\begin{array}{l}\text { Anterior } \\
\text { Processo: } \\
\text { - Seleção baseada em conhecimen- } \\
\text { tos tácitos, sem critérios objetivos. }\end{array}$ & $\begin{array}{l}\text { Atual } \\
\text { Processo: } \\
\text { - Etapa de definição objetiva dos } \\
\text { critérios de seleção. }\end{array}$ & $\begin{array}{l}\quad \text { Futuro } \\
\text { Processo: } \\
\text { - Descrever os procedimentos. } \\
\text { - Verificação e reavaliação constan- } \\
\text { te dos procedimentos. }\end{array}$ \\
\hline \multicolumn{3}{|c|}{ POP 8 - Recolhimento de produtos (reclamações) } \\
\hline $\begin{array}{l}\text { Anterior } \\
\text { Processo: } \\
\text { - Reutilização dos produtos reco- } \\
\text { lhidos apenas para alimentação } \\
\text { animal. }\end{array}$ & $\begin{array}{l}\text { Atual } \\
\text { Processo: } \\
\text { - Elaborando os critérios para clas- } \\
\text { sificar os produtos devolvidos e } \\
\text { definindo seu reaproveitamento. }\end{array}$ & $\begin{array}{l}\text { Processo: } \\
\text { - Descrever os procedimentos. } \\
\text { - Reaproveitamento dos produtos } \\
\text { com qualidade para os funcioná- } \\
\text { rios. } \\
\text { - Verificação e reavaliação constan- } \\
\text { te dos procedimentos. } \\
\end{array}$ \\
\hline \multicolumn{3}{|l|}{ POP 9 - Recepção de produtos } \\
\hline $\begin{array}{l}\text { Anterior } \\
\text { Processo: } \\
\text { - Manuseio baseado na informação } \\
\text { que apenas os funcionários envol- } \\
\text { vidos diretamente sabiam. } \\
\text { - Falta do controle da rastreabili- } \\
\text { dade. }\end{array}$ & $\begin{array}{l}\text { Atual } \\
\text { Processo: } \\
\text { - Descritos os procedimentos ope- } \\
\text { racionais das atividades. } \\
\text { - Uso de cartões com os dados do } \\
\text { local de colheita, para cada caixa. } \\
\text { - Implantado o controle da rastre- } \\
\text { abilidade. }\end{array}$ & $\begin{array}{l}\text { Futuro } \\
\text { Infraestrutura: } \\
\text { - Rampa para carreta, facilitando o } \\
\text { recebimento. } \\
\text { - Recebimento das caixas da lavou- } \\
\text { ra em paletes para facilitar o con- } \\
\text { trole e o manuseio. } \\
\text { Processo: } \\
\text { - Verificação e reavaliação constan- } \\
\text { te dos procedimentos. }\end{array}$ \\
\hline \multicolumn{3}{|c|}{ POP 10 - Procedimentos para preparo de produtos in natura } \\
\hline $\begin{array}{l}\text { Anterior } \\
\text { Infraestrutura: } \\
\text { - Tanque para lavar os tubérculos. } \\
\text { - Mesas de metal comum. } \\
\text { - Pouca disponibilidade de caixas. } \\
\text { - Gargalo no fluxo pela disponibili- } \\
\text { dade de etiquetadoras. } \\
\text { - Portas abertas sem obstáculos. } \\
\text { Processo: } \\
\text { - Existência de muitos fluxos cru- } \\
\text { zados. } \\
\text { - Atividades definidas apenas ver- } \\
\text { balmente. } \\
\text { - Produtos empilhados nas mesas } \\
\text { encostadas nas paredes, favore- } \\
\text { cendo o dano nos produtos em- } \\
\text { balados. }\end{array}$ & $\begin{array}{l}\text { Atual } \\
\text { Infraestrutura: } \\
\text { - Máquina de lavar tubérculos. } \\
\text { - Mesas de inox. } \\
\text { - Mais disponibilidade de caixas. } \\
\text { - Mais máquinas etiquetadoras. } \\
\text { - Cortinas transparentes nas portas. } \\
\text { Processo: } \\
\text { - Inovações drásticas nos fluxos. } \\
\text { - Descrição de todas as atividades. } \\
\text { - Mesas afastadas das paredes para } \\
\text { melhor circulação e para evitar o } \\
\text { empilhamento de produtos. } \\
\text { - Embalagem dos produtos e colo- } \\
\text { cação direta nas caixas, evitando } \\
\text { pilhas e danos nos produtos. }\end{array}$ & $\begin{array}{l}\quad \text { Futuro } \\
\text { Processo: } \\
\text { - Verificação e reavaliação constan- } \\
\text { te dos procedimentos. }\end{array}$ \\
\hline \multicolumn{3}{|c|}{ POP 11 - Embalagem e acondicionamento dos produtos in natura } \\
\hline $\begin{array}{l}\quad \text { Anterior } \\
\text { Processo: } \\
\text { - Embalagens sem pesos padroni- } \\
\text { zados. } \\
\text { - Uso de etiqueta simples. }\end{array}$ & $\begin{array}{l}\text { Prual } \\
\text { Processo: } \\
\text { - Padronização dos pesos das em- } \\
\text { balagens de acordo com a deman- } \\
\text { da dos varejistas. } \\
\text { - Etiquetas com código de barra. }\end{array}$ & $\begin{array}{l}\text { Futuro } \\
\text { Processo: } \\
\text { - Verificação e reavaliação constan- } \\
\text { te dos procedimentos. }\end{array}$ \\
\hline
\end{tabular}




\begin{tabular}{|c|c|c|}
\hline \multicolumn{3}{|l|}{ POP 12 - Expedição dos produtos } \\
\hline $\begin{array}{l}\text { Anterior } \\
\text { Infraestrutura: } \\
\text { - Produtos já embalados submeti- } \\
\text { dos à temperatura ambiente. } \\
\text { - Manuseio individual das caixas. } \\
\text { Processo: } \\
\text { - Processo de registro rudimentar. }\end{array}$ & $\begin{array}{l}\text { Atual } \\
\text { Infraestrutura: } \\
\text { - Instalada uma câmara de refrige- } \\
\text { ração. } \\
\text { - Carrinho para transportar blocos } \\
\text { de caixas. } \\
\text { Processo: } \\
\text { - Definição dos procedimentos. }\end{array}$ & $\begin{array}{l}\text { Futuro } \\
\text { Infraestrutura: } \\
\text { - Será instalada a segunda câmara } \\
\text { refrigerada. } \\
\text { Processo: } \\
\text { - Verificação e reavaliação constan- } \\
\text { te dos procedimentos. }\end{array}$ \\
\hline
\end{tabular}

Fonte: Elaboração dos autores.

Agora, a FOE está predominantemente na etapa inicial de reavaliação dos procedimentos. Essa situação é delicada e o entusiasmo inicial de implantação do POP já não é mais o ponto motivador para manter e desenvolver inovações. É fundamental instituir a rotina de verificar constantemente os procedimentos, reavaliar alternativas melhores, reescrever o novo procedimento, treinar para introduzir a nova mudança, efetivar a nova inovação e repetir indefinidamente essa atitude de aprendizagem e inovação.

\section{Conclusões}

A necessidade de certificação, mesmo que de forma compulsória, pode induzir a inovações. Essa possibilidade de melhoria depende da estrutura e dos recursos disponíveis da empresa submetida à demanda. No caso da "fazenda orgânica estudada" (FOE), observa-se que essa obrigatoriedade foi transformada de ameaça em oportunidade, de um ponto fraco em um ponto forte da empresa. A direção, os técnicos e os manipuladores da agroindústria orgânica usaram as exigências da certificadora de marca própria do grande varejista como um importante motivo para inovar. Essas características se aproximam da definição de Zollo e Winter (2002) de capacidade dinâmica, que é a capacidade da empresa de adaptar e recriar suas rotinas operacionais em razão de crises e mudanças do ambiente.

Analisando a cadeia produtiva orgânica de forma mais geral, observa-se o mesmo que Ormond (2002) já constatava. A agricultura orgânica é dependente da presença da certificadora. Entretanto, o caso estudado difere das observações deste autor, em que a figura do atacadista passa a ser executada pelo processamento primário e que o processador primário passa a desempenhar o papel da indústria integradora de outras cadeias. Neste estudo de caso, acontece outra realidade: o próprio produtor rural desenvolve o processamento primário e o grande varejo passa a ter papel de coordenador da cadeia produtiva.

No caso estudado, o varejo coordena diretamente os demais elos da cadeia produtiva e atua como um disseminador de inovações. Com a existência de grandes varejistas na coordenação da cadeia produtiva, surge a oportunidade 
Inovação Tecnológica na Agricultura Orgânica:

estudo de caso da certificação do processamento pós-colheita

para pesquisas futuras investigarem como os produtores orgânicos de pequeno porte estão se organizando e inovando para se adequarem às novas exigências técnicas de certificação.

Outro campo de novas pesquisas envolvendo a agricultura orgânica é o desenvolvimento de arranjos coletivos para inovações tecnológicas. Seguindo o exemplo do setor florestal brasileiro, cujas pesquisas evidenciam uma forte integração entre empresas, universidades e governo, gerando novos produtos e processos, segundo Montebello e Bacha (2009), a organização cooperada dos atores para a inovação na agricultura orgânica, seja na produção agropecuária ou nos processos de agroindustrialização, é um tema potencial para estudos futuros.

\section{Referências Bibliográficas}

ASSIS, Renato Linhares; ROMEIRO, Ademar Ribeiro. Agroecologia e agricultura familiar na região Centro-Sul do Estado do Paraná. Revista de Economia e Sociologia Rural - RESR. Vol. 43, n. 01, p. 155-177, 2005.

BATALHA, M. O.; SILVA. A.L. Gerenciamento de sistemas agroindustriais: definições e correntes metodológicas. In.: Batalha, M. O. (Coor.) Gestão agroindustrial: GEPAI; São Paulo: Atlas, 2001.

BELL, Martin. Background discussion paper for the L20 workshop. Furthering Science \& Technology. Maastricht: United Nations University Institute for New Technologies, 2006 http://www.120.org/publications/21_sY_Sci_background_Bell. pdf. Acesso em 09/01/2008.

BEZERRA, M.C.L.; VEIGA, J.E. (Coord.) Agricultura Sustentável. Brasília: Ministério do Meio Ambiente; Instituto Brasileiro do Meio Ambiente e dos Recursos Naturais Renováveis; Consórcio Museu Emílio Goeldi, 2000.

DAROLT, M. R. Agricultura Orgânica: inventando o futuro. Londrina: IAPAR, 2002.

DOSI, Giovanni. Mudança técnica e transformação industrial: a teoria e uma aplicação à indústria dos semicondutores. Campinas, SP: Editora da UNICAMP, 2006.

EHLERS, Eduardo M. O que se entende por agricultura sustentável? 1994. Tese (Mestrado em Ciência Ambiental) - Programa de Pós-Graduação FEA/USP, São Paulo.

HALL, Andy. Challenges to strengthening agricultural innovation systems: Where Do We Go From Here? Working Paper Series. Maastricht: United Nations University - Maastricht Economic and social Research and training centre on Innovation and Technology, 2007. http://www.merit.unu.edu/publications/ wppdf/2007/wp2007-038.pdf. Acesso em 09/01/2008. 
INTERNATIONAL ORGANIZATION FOR STANDARDIZATION - ISO. Publicizing your certification. http://www.iso.org/iso/en/iso9000-14000/publicizing/ publicizing_6.html. Acesso em 26/01/2005.

MACHADO, Rosa Teresa Moreira. Fundamentos sobre o estudo da dinâmica das inovações no agribusiness. Revista de Administração Contemporânea - RAC. Vol. 2, n. 2, p. 127-141, 1998.

MARTINS, Gilberto de Andrade. Estudo de Caso: Uma Estratégia de Pesquisa. São Paulo: Atlas, 2006.

MAZOYER, Marcel; ROUDART, Laurence. Sustainability of agricultures and globalization. In.: CRISTOIU, Adriana et al. Sustainability of the farming systems: global issues, modelling approaches and policy implications. Institute for Prospective Technological Studies, 2007.

MELLO, Átila Pimentel Rocha. O desenvolvimento de competências essenciais como fonte de vantagem competitiva na estratégia de internacionalização de negócios: o caso do consórcio Flor-Brasil. 2004. Dissertação (Mestrado em Administração) Faculdade de Economia, Administração, Contabilidade e Ciência da Informação e Documentação. Universidade de Brasília, Brasília.

MONTEBELlO, Adriana Estela Sanjuan; BACHA, Carlos José Caetano. Avaliação das pesquisas e inovações tecnológicas ocorridas na silvicultura e na produção industrial de celulose no Brasil. Revista de Economia e Sociologia Rural RESR. Vol. 47, n. 2, p. 485-517, 2009

NASSAR, André M. Certificação no agribusiness. In: Zylbersztajn, D; Sacre, R.F. (Org.). Gestão da qualidade no agribusiness: estudo e casos. São Paulo, Atlas, 2003.

NAVARRO, Zander. Desenvolvimento rural no Brasil: os limites do passado e os caminhos do futuro. Estudos Avançados. Vol. 15, n. 43, 2001.

NELSON, R.; WINTER, S. Uma teoria evolucionária da mudança econômica. Campinas, SP: Editora da UNICAMP, 2005.

ORMOND, J.G.P. et al. Agricultura orgânica: quando o passado é futuro. Rio de Janeiro: BNDES, 2002. http://www.bndes.gov.br/conhecimento/bnset/set1501. pdf Acesso em 02/02/2005.

SAHOTA, By Amarjit. Overview of the global market for organic food and drink. In. Willer, H.; Yussefi, M. The world of organic agriculture: Statistics and Emerging Trends. Bonn: International Federation of Organic Agriculture Movements IFOAM, 2004.

SCHUMPETER, Joseph A. Capitalismo, Socialismo e Democracia. Editora Fundo de Cultura. Rio de Janeiro, 1984. 
SPERS, Eduardo Eugênio. Qualidade e Segurança em Alimentos. In: Zilberztajn, N. Economia e Gestão dos Negócios Agroalimentares. Pioneira, São Paulo, 2000.

VALDINOCI, Mario. Agricoltura e nuova società. Roma: Natura e Cultura, 1979.

VEIGA, José Eli da. O desenvolvimento agrícola: uma visão histórica. São Paulo: Editora da Universidade de São Paulo: HUCITEC, 1991.

VOSSENAAR, R.; JHA, V.; WYNEN, E. Trading opportunities for organic food products from developing countries. In: UNCTAD. Trading opportunities for organic food products from developing countries. New York and Geneve: United Nations Publication, 2004.

WILLER, Helga; SORENSEN, Neil; YUSSEFI-MENZLER, Minou. The world of organic agriculture: statistics \& emerging trends 2008. Bonn: International Federation of Organic Agriculture Movements - IFOAM, 2008. http://orgprints. org/13123/4/world-of-organic-agriculture-2008.pdf. Acesso em 22/08/2010.

YIN, Robert K. Estudo de Caso: Planejamento e Métodos. 2 ed. Porto Alegre: Bookman, 2001.

ZOLLO, Maurizio: WINTER, Sidney. Deliberate learning and the evolution of dynamic capabilities. Organization Science. Vol. 13, n. 3, p. 339-351, 2002. 